\title{
INTERACTIONS OF PERIPHERALLY AND CENTRALLY ORIGINATING INPUT TO ASSOCIATION CORTEX'
}

\author{
L. T. RUTLEDGE \\ Department of Physiology, University of Michigan, Ann Arbor, Mich. (U.S.A.)
}

(Received for publication: February 13, 1963)

An important addition to facts of cerebral cortical physiology has been the recent recognition that the cortex is not a strictly divided structure in terms of either afferent or efferent activity. In the unanesthetized animal both sensory and motor functions are found over wide cortical areas. Lilly (1958), Hughes (1959), and Hughes and Mazurowski (1962) have described and emphasized the consistency of patterns of motor activity originating from nearly the entire cortical surface. Widespread multimodality afferent discharge to cortex has received most intensive study by Buser and coworkers (Buser and Borenstein 1957b, 1959; Buser et al. 1959). Other investigators (e.g., Berman 1961a, b) have carefully studied two modalities of input to restricted areas of the cerebral cortex. Even the motor cortex receives polysensory afferent discharges (Buser and Imbert 1961). Convergence or interaction from remote cortical areas is also receiving attention (Hotta and Takenaka 1962; Burns and Smith 1962).

Polysensory input is most readily recorded in association areas outside of the classical primary projection cortex. In addition to peripherally originating afferent discharge, at least one of the cortical association areas in the cat, the middle portion of the suprasylvian gyrus, has been shown to receive input from nonspecific subcortical structures (Buser and Borenstein 1957a; Rutledge and Kennedy 1961 ; also Morillo 1961, but suprasylvian locus unspecified) and from contiralateral cortex. The contralaterally originating inputs, as defined electrophysiologically, are the transcallosal response (TCR) and the interhemispheric de-

\footnotetext{
1 Aided by grant B-2978 from the National Institute of Neurological Diseases and Blindness and Senior Research Fellowship GM-K3-15, 122 from the U.S. Public Health Service.
}

layed response (IDR) (Rutledge and Kennedy 1960).

The most definitive approach to an appreciation of the importance of converging input to association cortex is probably by way of a single cell analysis. Amassian (1954) mentioned that some cells in the anterior lateral gyrus could be discharged by somatic or auditory stimulation. Latimer and Kennedy (1961) found that about half of the units fired by a transcallosal volley were also fired by peripheral stimulation. A few units in the latter study fired in synchrony with both the TCR and IDR waves. Current work in our laboratory has indicated that in the cat's suprasylvian gyrus there is an imperfect convergence of polysensory input onto individual cells. This appears to be the case from Imbert's (1960) preliminary report as well. Such differential responsiveness at the cellular level should be expected if discriminative integrative properties charasterize association cortex. Until unit data are complete an analysis of convergent inturaction can be made with evoked potential slow waves.

The IDR was shown to interact in suprasylvian gyrus with subcortical input and, in preliminary experiments, with at least photically evoked potentials (Rutledge and Kennedy 1961). The present report, a continuation of our previous work, is directed toward determining the extent of evoked potential interaction among peripherally and centrally originating input to the suprasylvian gyrus and certain other cortical areas.

Chloralose preparations were used for greater stability of evoked responses. Barbiturate anesthesia is not appropriate since in this state polysensory input to association cortex is abolished. For this reason no attempt has been made to equate or discuss present results with those obtained from animals under barbiturate anesthesia.

Electroenceph. clin. Neurophysiol., 1963, 15: 958-968 


\section{METHODS}

This paper is based upon results obtained from 20 cats, the third group of animals in the completed series of experiments on the interhemispheric delayed response. (A fourth set of experiments will comprise a unit study of polysensory input to association cortex.) The method was essentially that of our previous work (Rutledge and Kennedy 1960, 1961) but with several refinements.

Photic stimulation was by a General Electric No. 327 bulb mounted in a $17 \mathrm{~mm}$ reflector and driven by a Grass S-4 Stimulator set at $5 \mathrm{msec}$ duration and 65 to $100 \mathrm{~V}$. This lamp operates without any sound; other characteristics of the lamp have been discussed in detail (Doty 1958). The reflector was mounted in the midline about $5 \mathrm{~cm}$ from the dilated pupils. Room illumination was greatly reduced. Auditory stimulation was by means of an audio amplifier and speaker controlled by a Grass Stimulator. Click duration was $0.1 \mathrm{msec}$ and intensity was suprathreshold to that necessary for evoked potentials in primary auditory cortex. Hollow earbars were used on the stereotaxic instrument. Somesthetic stimulation to contralateral forelimb footpad by means of inserted needles was controlled by a Grass Isolation Unit and Stimulator. Intensity of the 0.5 to $1.0 \mathrm{msec}$ pulse was suprathreshold to that giving evoked potentials in somatosensory cortex but subthreshold for limb reflex twitch.

Electrical stimulation of the brain was via a Grass Isolation Unit and Stimulator. Careful isolation from ground was observed.

Cortical surface recordings, always contralateral to cortical stimulation, were from unipolar silver balls paired with an indifferent metal screw inserted in the midline near the lambdoidal crest. Amplifier time constant was $0.2 \mathrm{sec}$. The suprasylvian recording site was in the region of frontal 8-10 and lateral 8-10 (Jasper and Ajmone Marsan Atlas 1954), homotopic to the cortical stimulating electrodes. Recordings from the anterior marginal gyrus were made from the vicinity of frontal 18-20 and lateral 4-6. Bipolar silver bails approximately $2 \mathrm{~mm}$ apart were used for cortical stimulation. Concentric bipolar depth electrodes were stereotaxically placed. These electrodes were insulated up to the sharpened exposed tips which were $0.5 \mathrm{~mm}$ apart. Depth locations, in the general area of frontal 3, lateral 3, and horizontal -1.5, were also chosen from the Jasper and Ajmone Marsan Atlas and were histologically verified.

The use of an average response computer (Mnemotron C.A.T.) was routine in the later experiments. Computer readout was accomplished by photographing the computed averaged records displayed on a slave CRO.

\section{RESULTS}

Evoked potential slow waves at cortex were studied with stimulation of visual, somesthetic, and auditory systems and of the mesencephalic reticular formation and contralateral suprasylvian cortex. All combinations of conditioning test interactions were investigated, but hecause of time limitations it was not possible to accomplish a complete series, using all stimuli, in every animal. Attention was directed toward determining critical "blocking" interaction times as a measure of relative accessibility of the various inputs to a given cortical field.

TABLE I

Average latencies and ranges in msec of late wave evoked potentials in suprasylvian gyrus

\begin{tabular}{|c|c|c|c|c|c|c|c|c|}
\hline \multirow{2}{*}{$\begin{array}{l}\text { Major } \\
\text { positive wave }\end{array}$} & \multicolumn{2}{|r|}{ Visual } & \multicolumn{2}{|r|}{ Auditory } & \multicolumn{2}{|r|}{ CFP } & \multicolumn{2}{|r|}{ IDR } \\
\hline & $N^{*}$ & Mean (range) & $N^{*}$ & Mean (range) & $N^{*}$ & Mean (range) & $N^{*}$ & Mean (range) \\
\hline Onset & 17 & $\begin{array}{c}44 \\
(25-65)\end{array}$ & 8 & $\begin{array}{c}23 \\
(15-40)\end{array}$ & 4 & $\begin{array}{c}29 \\
(25-30)\end{array}$ & 10 & $\begin{array}{c}46 \\
(35-65)\end{array}$ \\
\hline Peak & 18 & $\begin{array}{c}60 \\
(35-80)\end{array}$ & 11 & $\begin{array}{c}47 \\
(30-65)\end{array}$ & 5 & $\begin{array}{c}46 \\
(38-60)\end{array}$ & 12 & $\begin{array}{c}66 \\
(45-30)\end{array}$ \\
\hline
\end{tabular}

- $N=$ number of different experiments from which accurate measurements could be made, either from repeated sets of superimposed oscilloscope traces or from averaged computer records. CFP: contralateral forepaw; IDR: interhemispheric delayed response. 


\section{Slow wave charasteristics}

Neither peripherally nor centrally originating discharges arrive in association cortex with identical latencies, either to the onset of the late wave, the major positive deflection, or to its peak. Table I shows average and range values. Actual records may be seen in Fig. 1-7. The major positive deflection was not always the first wave seen. Small "primaries" were sometimes recorded but they could always be distinguished from the later waves on the basis of interaction with other inputs. The primaries could not be blocked; neither could the TCR be made to interact with late waves.

Photic stimulation and electrical stimulation of the contralateral ovrus evoked waves with similar latencies, but the photically evoked po- tential rose to its peak earlier and was of shorter duration than the IDR. Auditory and somesthetic inputs to suprasylvian association cortex had similarlatencies. Thelatencies of responses evoked by mesencephalic reticular stimulation were shortest of all, with average values, in the experiment of Fig. 5 and in others, of about 6 and 20 msec to onset and peak of the waves respectively.

As shown in Table I, the number of experiments in which it was possible to study systematically late waves to various inputs, reflects precisely the ease of elicitation of the evoked potentials. Photic flash was most effective, followed in order by contralateral cortical (IDR), mesencephalic reticular, auditory, and somesthetic stimulation. In some experiments photic flash was
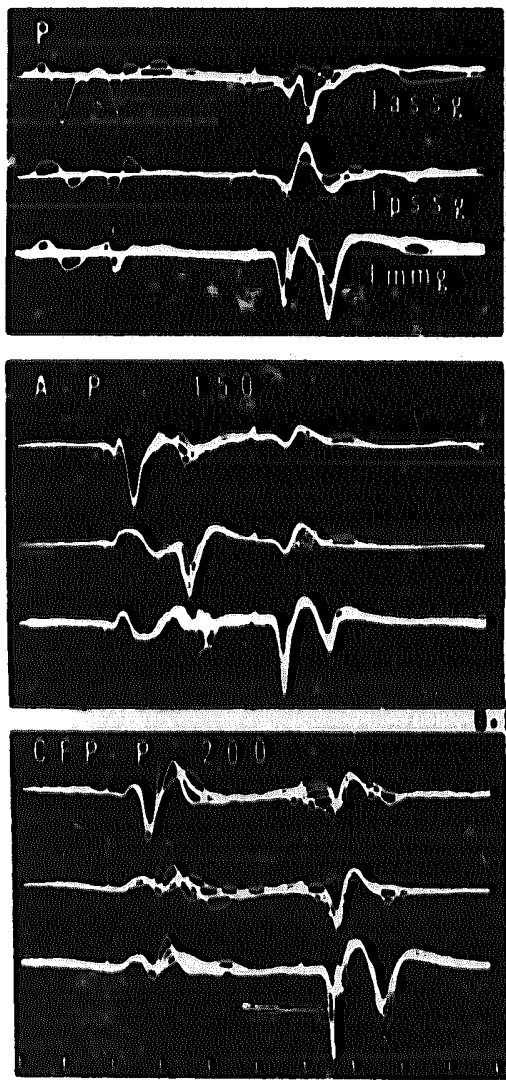

50 m80
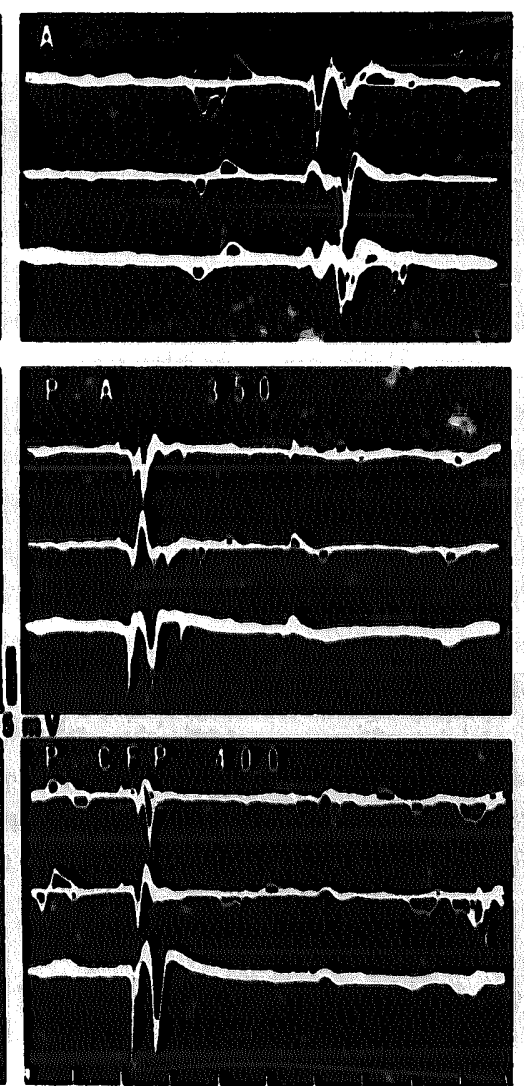

1000808
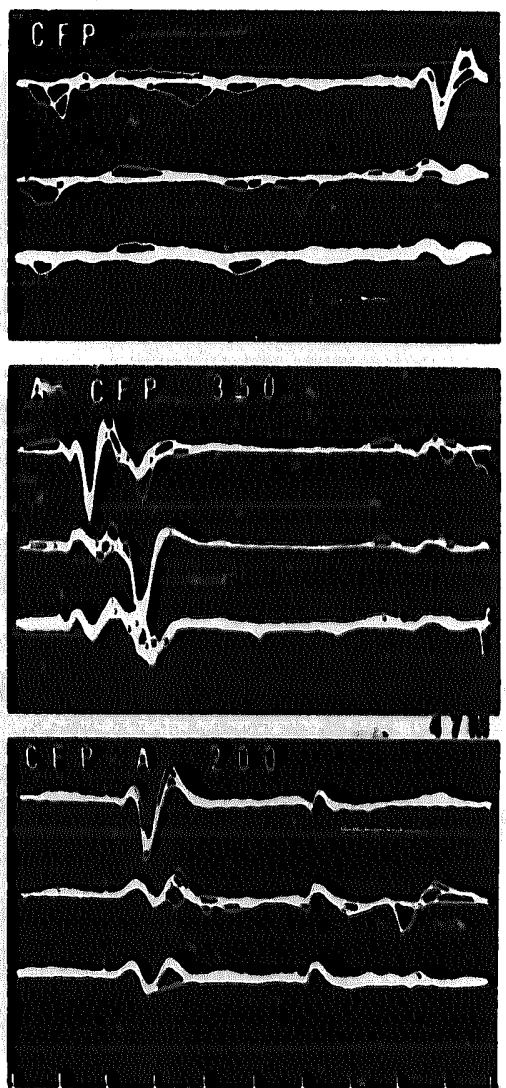

30 เove

Fig. 1

Interactions of responses to peripheral stimuli. Superimposed sweeps at 1/6 sec. First tracing (lassg): left suprasylvian gyrus, anterior; second (lpssg): left suprasylvian gyrus, posterior; third (lmmg): left marginal (lateral) gyrus anterior to primary visual cortex (see recording sites in diagram of Fig. 6). P: maximal responses to $5 \mathrm{msec}$ photic fash; A: maximal responses to 0.1 msec auditory click; CFP: maximal responses to stimulation at $0.5 \mathrm{msec}$ duration, $4 \mathrm{~V}$, to contralateral forepaw. Interaction records at longest $\mathrm{C}-\mathrm{T}$ intervals giving maximal block on test responses. In this and in Fig. 2-5 the number above the top tracing represents the interval (in $\mathrm{msec}$ ) between the iwo stimuli. Downward defiections are positive in all figures. 
the only effective stimulus, and photic stimulation was always effective if responses were seen to auditory or somesthetic stimulation. It was rarely possible to demonstrate the presence of an IDR without responses being seen at least to photic stimulation.

No systematic attempt was madetostudy other association areas but in several experiments responses evoked in the anterior marginal gyrus were investigated. Latencies for visual and somesthetic inputs appeared to be identical here at 30 and 50 msec for onset and peak of the waves. Auditory input had a shorter latency at 18 and 38 msec. Contralateral suprasylvian gyrus stimulation frequently produced a response in this area with latencies similar to auditory input. Areal differences and ease of response elicitation for the various inputs could not be related to depth of anesthesia, temperature, or other factors.

\section{Interactions of inputs to association cortex}

Peripheral. Fig. 1 is a summary set of conditioning-test interactions at three cortical locations. Contro! responses (test) to visual, auditory, and somesthetic stimulation are in the upper three frames. The photic evoked potential at all loca- tions consists of a $180 \mu \mathrm{V}$ to over $800 \mu \mathrm{V}$ primary followed by a later positive wave peaking at 60 insec at the most anterior suprasylvian locus and at 75 msec elsewhere. Auditory stimulation likewise evoked a response at the three sites. The CFP stimulation, however, evoked the largest response in the most anterior suprasylvian locus.

Blocking interactions for any two responses were not reciprocal (Fig. 1). The photic elicited response had an extremely powerful blocking effect, lasting for $350 \mathrm{msec}$, on the response to an auditory click. The limit for maximum auditory input effect on the photic was only 150 msec. Note that in primary visual cortex (third trace) the auditory evoked response incompletely blocked the second positive-negative wave to photic and actually enhanced the photic primary evoked potential. If one defines strength of input in terms of the effective C-T blocking interval it is apparent from Fig. 1 that visual is most powerful. This is followed by auditory and somesthetic.

Cortical-peripheral. For comparative purposes Fig. 1, 2, 5, 6 and 7 are reords from the same experiment. Fig. 2 shows records of interactions of peripherally originating input with responses to contralateral cortex stimulation (IDR). A large IDR was seen at the three locations.
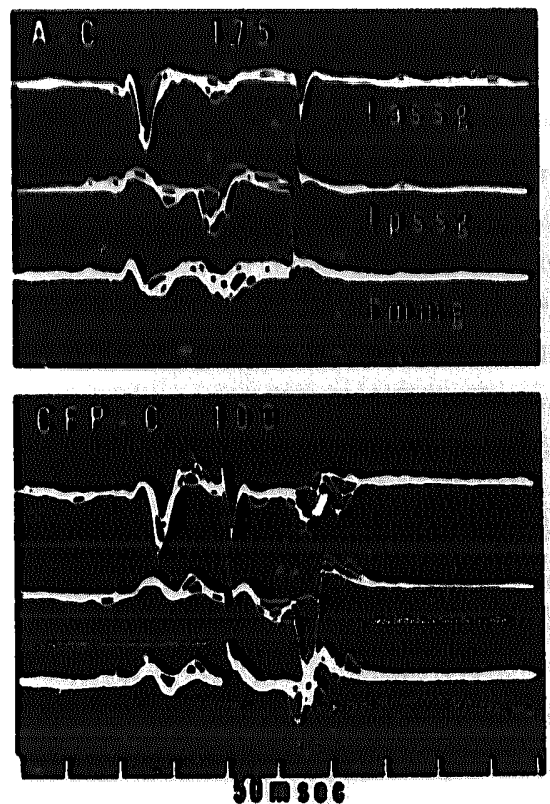

$5 0 \longdiv { 8 0 6 }$
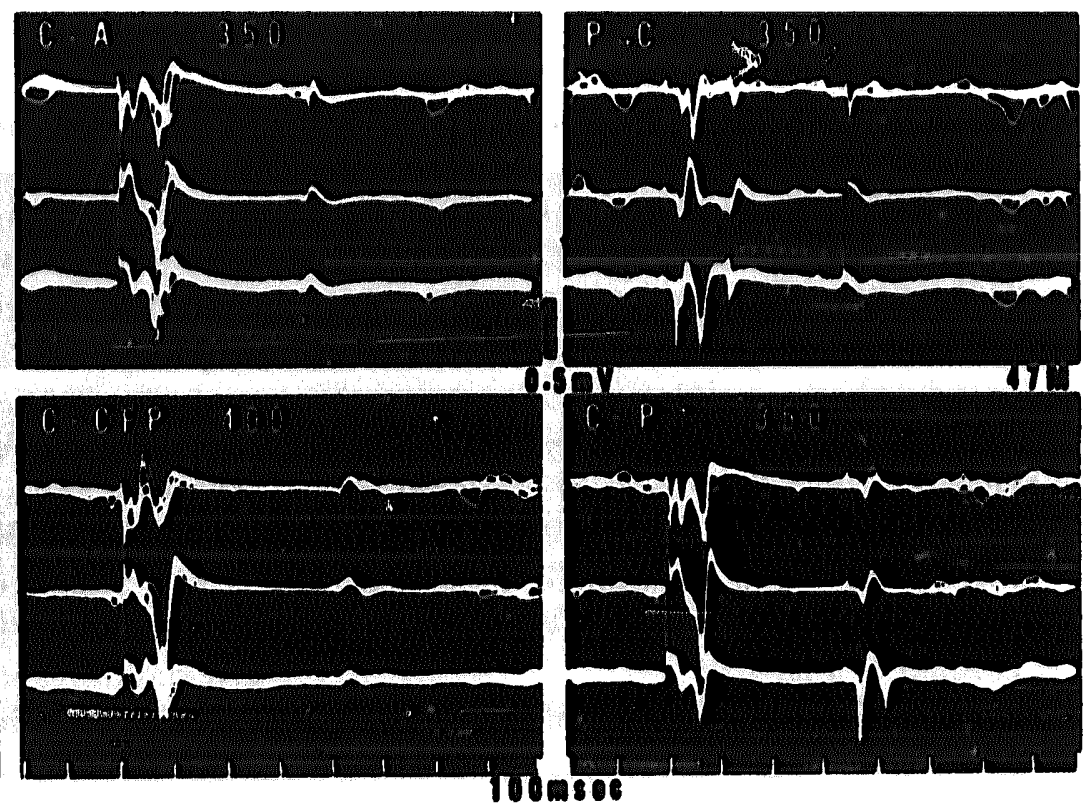

Fig. 2

Interactions of responses to peripheral stimulation and to electrical stimulation of contralateral midsuprasylvian gyrus. $C$ : responses to bipolar cortical stimulation at 0.2 msec duration, 11 V. (Continuation of experiment in Fig. 1.) 

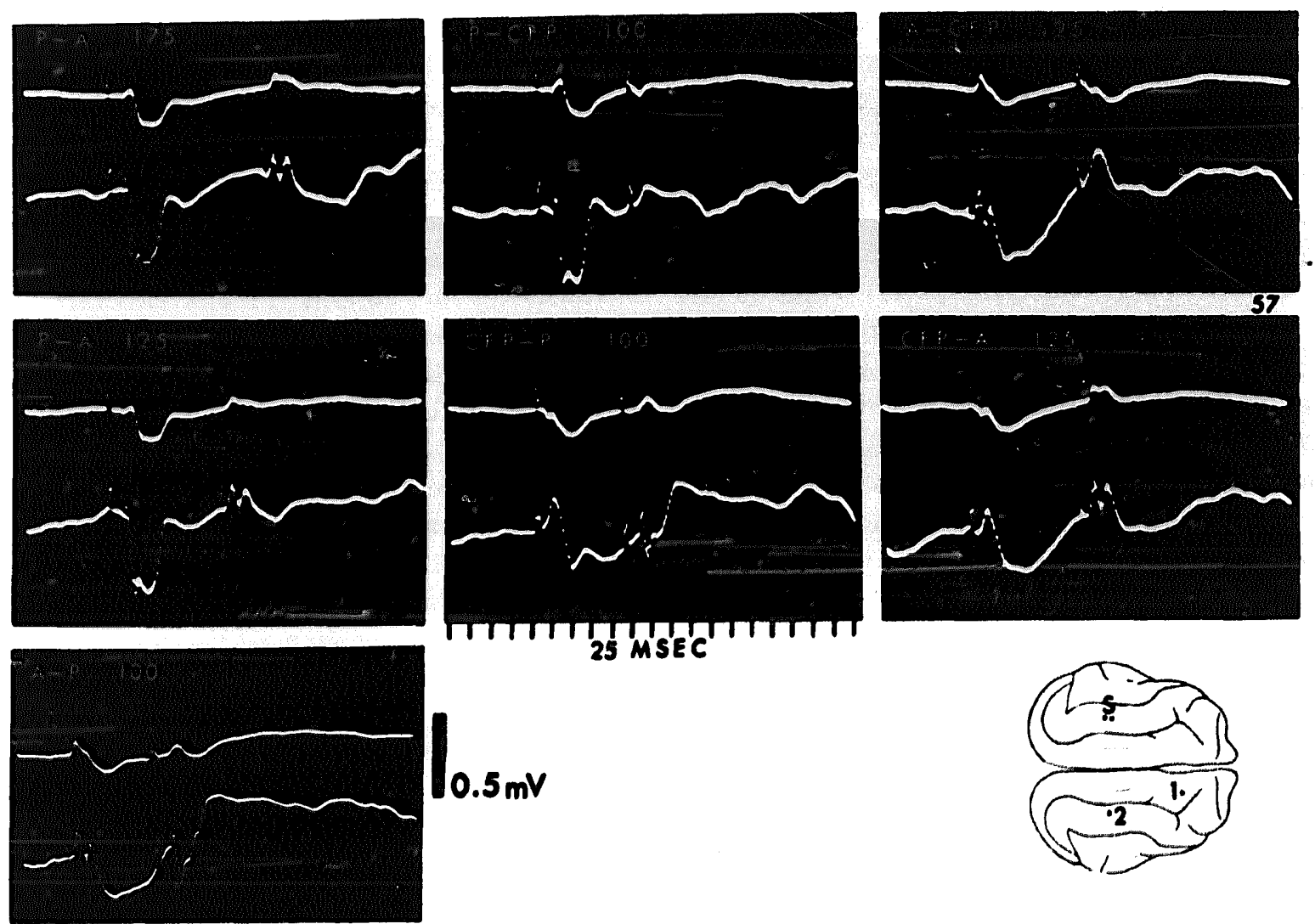

Fig. 3

Comnuter analyses, in association cortex, of interactions of responses to peripheral stimuli. Recording sites in diagram: I (first tracing): marginal (lateral) gyrus; 2 (second tracing): suprasylvian gyrus. Stimuli adjusted to give maximal responses. P: photic flash, 5 msec duration; A : auditory click, 0.1 msec duration: CFP: contrulateral forepaw, 0.5 msec duration, $9 \mathrm{~V}$. Each record is an average of 50 sweeps taken at $1 / 2.5$ sec.

The IDR had its strongest blocking effect upon the somesthetic input, as strong as the photic input effect on somesthetic seen in Fig. 1. However, cortical and photic input interaction was not perfectly reciprocal. In the last column of Fig. 2 at C-P 350 a portion of the later, second response to photic stimulation still remains. In many experiments the superiority of the photic blocking effect was cven more pronounced than in this record.

Both auditory and somesthetic input had a markedly weak effect on the IDR, as show' $n$ in the first column of Fig. 2.

From Fig. 2 the empirically defined hierarchy of input from strongest to weakest is seen to be: visual, IDR, auditory, and somesthetic.

Computer analyses of peripheral and cortical interactions. Fig. 3 and 4 are computer averaged records of another experiment. In some respects averaged responses are more difficult to interpret than are superimposed records. A small consistent remnant of a primary response or a consistent potential shift of very long duration, if neither is blocked by interaction, tend to be emphasized relative to the more inconsistently evoked potentials. In other instances, a blocked response may reveal an underlying potential not otherwise apparent, as is sess in Fig. 3, A-P 100 and CFP.P 100.

Fig. 3 shows, at two association cortex locations, blocking interactions between peripherally originating responses. Relative to other modalities, though not as absolutely effective as in many other experiments (e.g.. Fig. 1), photic used as the conditioning stimulus produced the longest blocking interval. In the Fig. 3 records reciprocal comparisons were made at comparable times between visual-somesthetic and auditory-somes- 

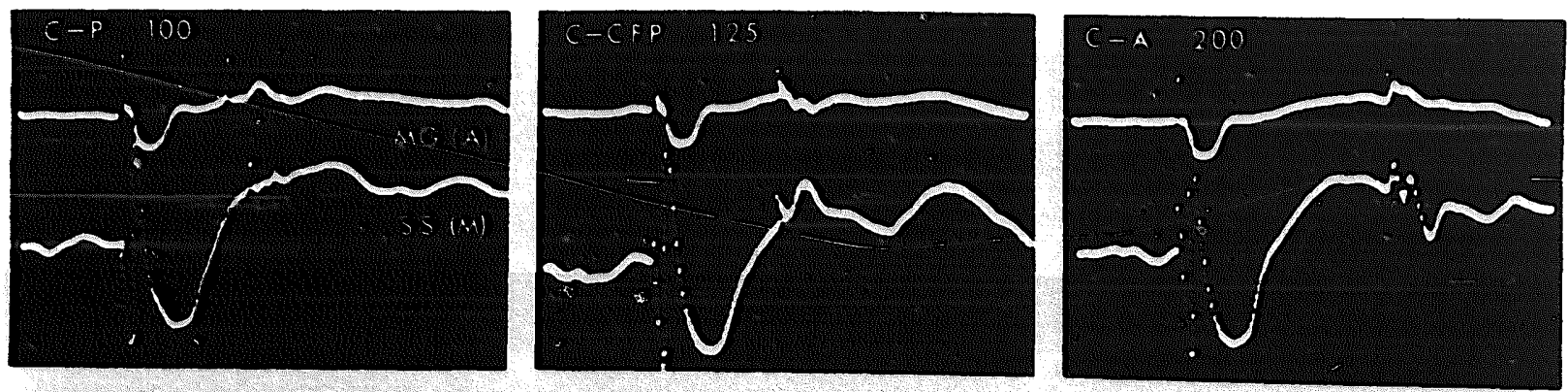
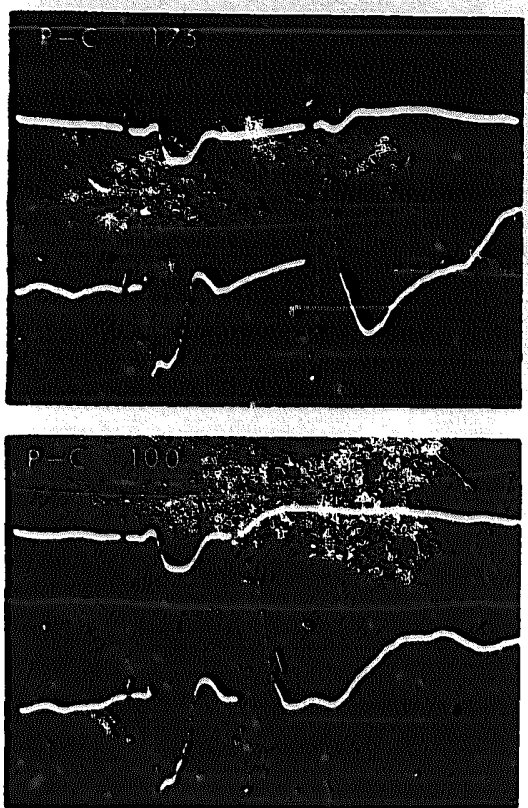

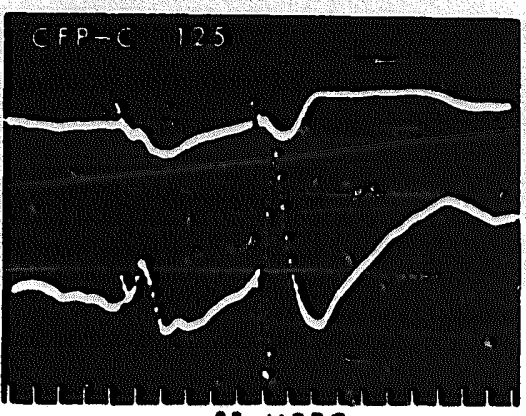

25 MSEC

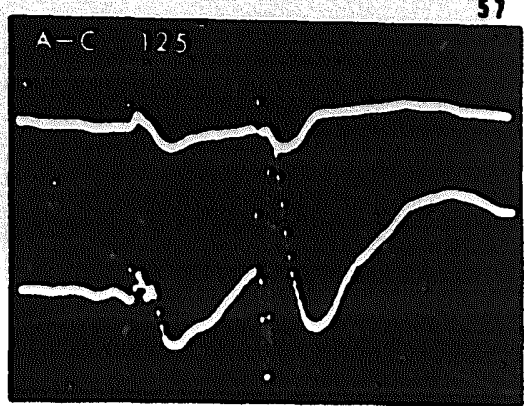

Fig. 4

Computer analyses of responses to peripheral stimulation and to electrical stimulation of contralateral mid-suprasylvian gyrus. C: responses to bipolar corticat stimulation at $0.1 \mathrm{msec}$ duration, $12 \mathrm{~V}$. Transcallosal response retouched. (Continuation of experiment in Fig. 3.)

thetic. Measurements indicate that reciprocal blocking effects do not occur. In the case of auditory-somesthetic there is a suggestion of a difference at the two locations. Somesthetic appears to be a bit stronger in marginal gyrus and visual perhaps stronger in suprasylvian.

Fig. 4 is similar to Fig. 2. The IDR and photic interactions again show photic to be stronger. Comparable C-T intervals are frames one and three. The IDR had a stronger blocking effect on auditory input but somesthetic and auditory were equally effective on the IDR.

\section{Mesencephalic reticular formation-peripheral}

As discussed in our previous papers the mesencephalic reticular formation (MR) is the likely interhemispheric relay for the IDR. In Fig. 5 are records of interactions of responses to peripheral and subcortical (MR) stimulation. Interpreting records as before, both the photic and auditory inputs are "stronger" (there is a longer effective blocking C-T interval) than the MR elicited response. Somesthetic input is unquestionably the weakest.

Although the MR-IDR records are not shown for this experiment, MR input was unquestionably weaker than the IDR. Reciprocal interaction between the cortical response elicited by stimulation of the supposed IDR relay might be expected, but this is not the usual result. Note in Fig. 5 that the response to MR stimulation begins at less than 10 and peaks at about 20 msec. The IDR at the same locus begins at 20 and peaks at about $40 \mathrm{msec}$ (see Fig. 2).

The importance of an MR influence on cortical responses originating from the periphery is 

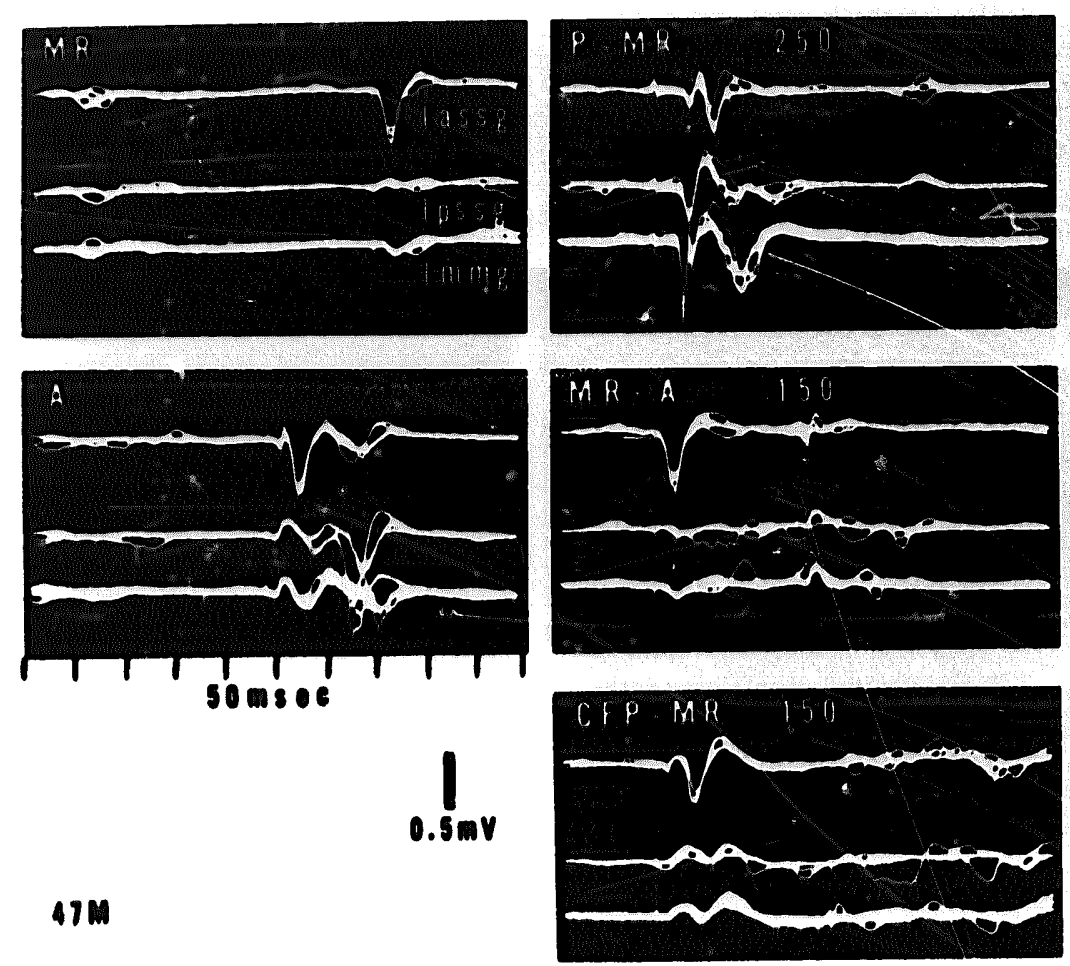

Fig. 5

47M
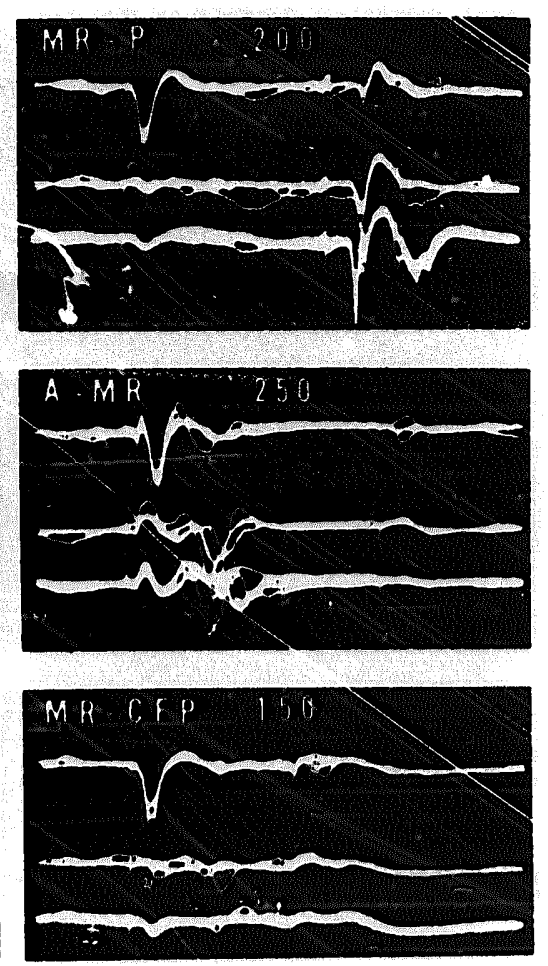

Interactions of responses to peripheral stimulation and to electrical stimulation of ipsilateral mesencephalic reticular formation (MR) histologically verified at stereotaxic coordinates, frontal 2.5, lateral 2, horizontal $=1$. Concentric electrode, bipolar MR stimulation at $0.1 \mathrm{msec}$ duration, $2.2 \mathrm{~V}$ for maximal responses. Interaction records at longest C-T intervals giving maximal block on test responses, (Continuation of experiment in Fig. $I$ and 2.)

demonstrated by the facilitation records of Fig. 6. The left column shows maximal responses obtainable to photic (Fig. $6, A$ ) and MR (Fig. 6, C) stimulation. In Fig. 6, B, photic flash in. tensity was reduced so that barely detectable responses were seen. In Fig. 6, D, subthreshold photic stimulation was followed in $50 \mathrm{msec}$ by MR stimulation at the intensity used in $C$. In the first tracing of Fig. $6, D$, there is only a suggestion of slight summation of the negative wave. In the other two tracings there is a distinct facilitation of later waves. Remnants of the primary photic response were not altered by different C-T intervals. Under these conditions this true facilitation must have occurred exclusively on cells discharging the later, secondary waves of the evoked photic response.

In all modalities studied, convergence producing a facilitated response is easily demonstrated by means of single shock MR stimulation. If both inputs are subthreshold the facilitated response closely resembles the response to supra- threshold stimulation of either input alone. Fig. 7 depicts facilitation with converging MR and somesthetic input. In the first column are maximal responses; in the second are subthreshold responses. Virtually no electrical discharge was evoked. When these subthreshold stimuli were combined (third column) the facilitated responses had latencies somewhat between those of the two maximal responses. The facilitated response latency could be shifted back and forth depending upon MR stimulation delay time. With MR stimulation delayed about $20 \mathrm{msec}$ the facilitated responses were nearly identical with those to suprathreshold somesthetic stimulation alone. With decreasing delays the onset and peak of the racilitated response would shift accordingly toward the shorter latency of the response to MR stimulation.

A considerable amount of summation of submaximal responses to any pair of stimuli was virtually always seen. Although convergence underlies both facilitation and summation the 

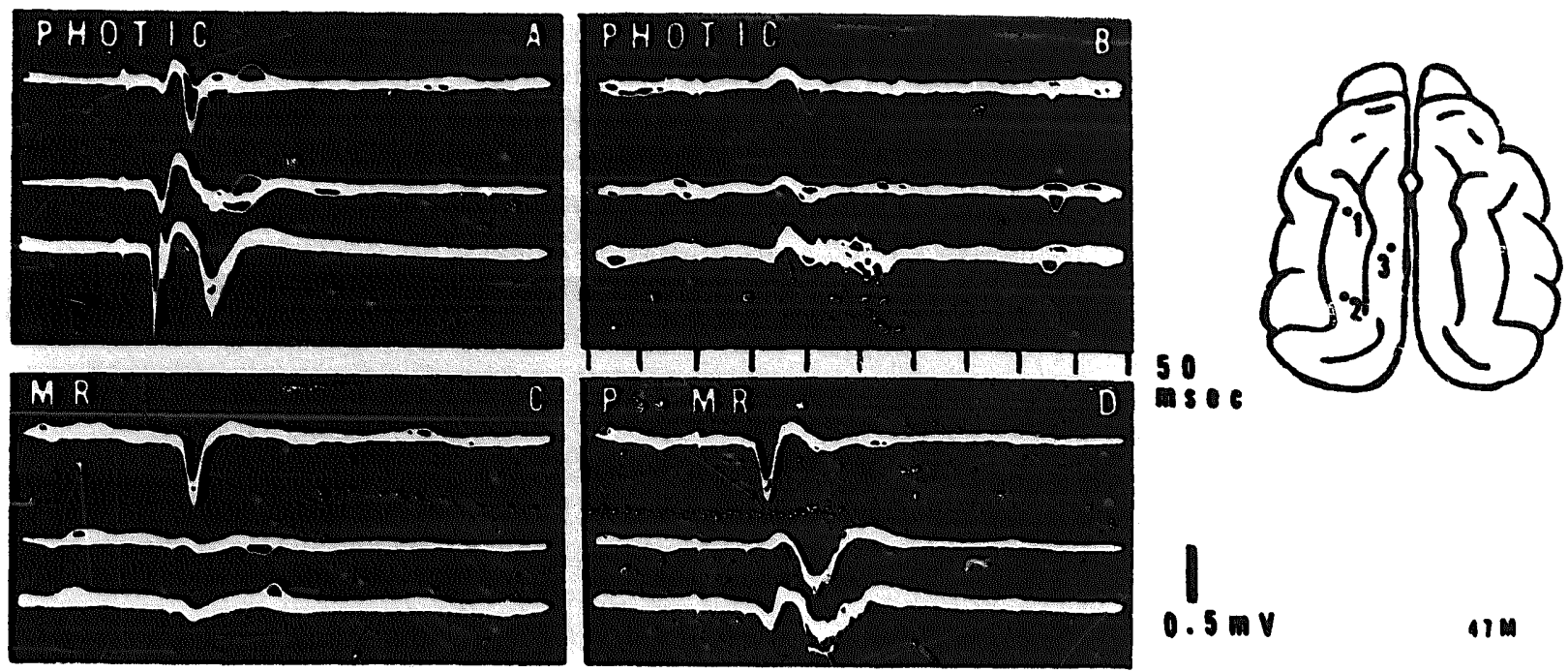

80

Fig. 6

Facilitation of subthreshold photically evoked cortical responses by ipsilateral mesencephalic reticular formation (MR) stimulation. MR location histologically verified at stereotaxic coordinates, frontal 2.5, lateral 2, horizontal -1 . Recordings as indicated in diagram. $A$ : maximal responses to photic flash of 5 msec duration; $B$ : responses to much reduced photic flash intensity; $C$ : maximal responses to MR stimulation of 0.1 msec duration, $3 \mathrm{~V} ; D$ : MR stimulation, for maximal responses, $50 \mathrm{msec}$ after photic flash. (Same experiment as Fig. 1.)
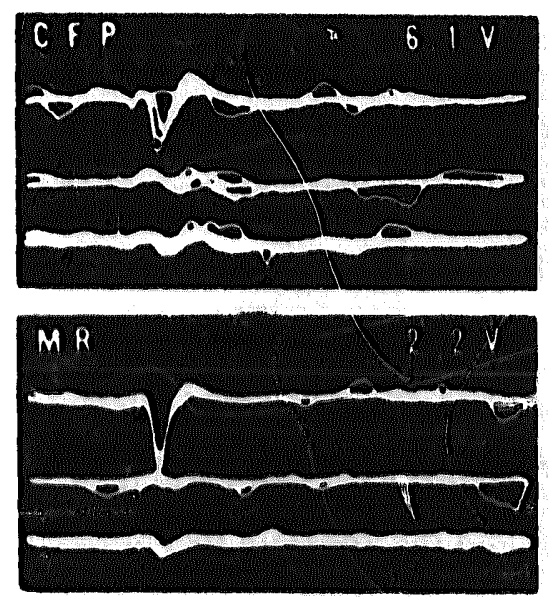
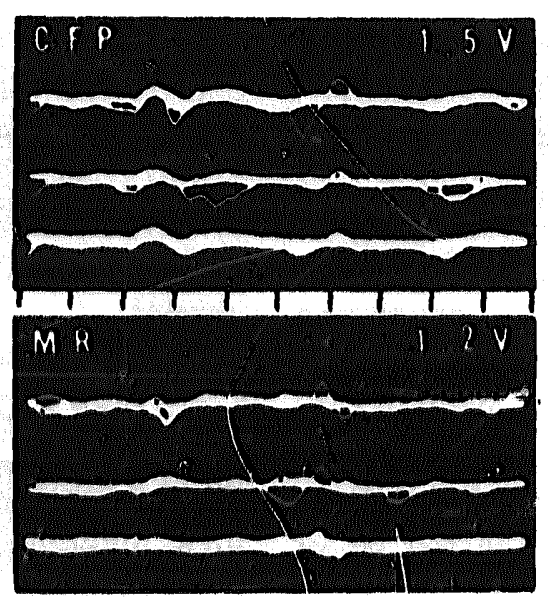
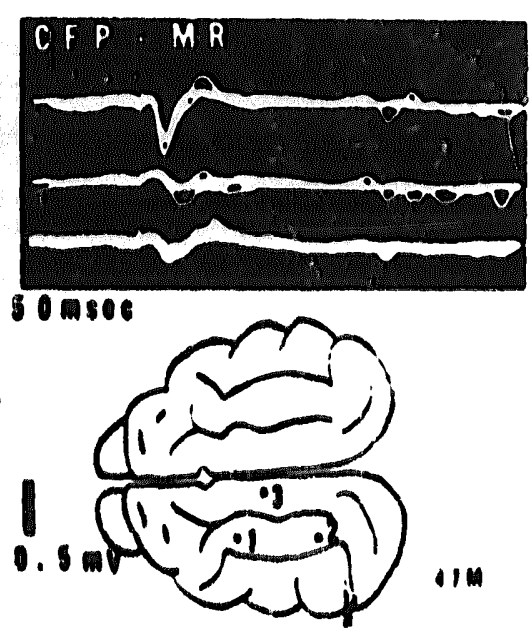

Fig. 7

Facilitative interaction in cortex following subthreshold ipsilateral mesencephalic reticular formation (MR) and contralateral forepaw (CFP) stimulation. MR location histologically verified at stereotaxic coordinates, frontal 2.5, lateral 2, horizontal -1. Recordings as indicated in diagram. Upper left frame CFP: maximum responses to stimulation of $0.5 \mathrm{msec}$ duration, $6.1 \mathrm{~V}$. Lower left frame MR: maximum response to stimulation of $0.1 \mathrm{msec}$ duration, $2.2 \mathrm{~V}$. CFP + MR: responses to subthreshold stimuli, as shown in column 2, given together. (Same experiment as Fig. 1.)

former is distinguished by conditions where at least one of the two stimuli does not produce a response.

In addition to facilitation and summation a neuronal pool activated by converging inputs from several sources could demonstrate inhibition and occlusive interaction. However, the long blocking interaction times observed rule out simple occlusive interaction based unon relatively short refractory times. A true inhibitory process operating on the neurons in the pool but not generated by specific inhibitory input is a likely explana- 
tion (unsupported by direct data), for the long periods of blocking interactions resulting from suprathreshold conditioning stimulation. Prolonged hyperpolarization following cortical neuronal activity has been observed by several workers and was most recently investigated by $\mathrm{Li}$ and Chou (1962).

\section{Discussion}

These experiments have established the following. (1) At the same locus in the association cortex of cats under chloralose anesthesia evoked potentials can be reliably recorded to photic, auditory, and somesthetic peripheral stimulation and to central electrical stimulation applied to the contralateral suprasylvian gyrus or to the mesencephalic reticular formation (MR). (2) Blocking interactions occur at the cortex between various pairs of the five inputs used. (3) Under the present experimental conditions blocking interactions are not reciprocal or of equal efficiency. This empirical finding has been used to define a descending hierarchy of input importance: photic, IDR, MR, auditory-somesthetic. (4) True facilitation and summation on association cortex late wave slow potentials by the MR was demonstrated.

As a supposed integrative area of the carebral cortex it is not surprising that association cortex receives discharges from both peripheral and central sources. In spite of the fact that the experimental design necessitates some caution concerning adequacy of receptor activation, the unnatural nature of electrical stimulation, etc., it should not be expected that the degree or amount of convergence would be intrinsically the same for all input systems. Interactions of the various inputs were not seen to be reciprocal. Some are distinctly stronger than others (i.e., there is more convergence) and this finding is probably directly related to the relative functional importance of the various systems. For a given species it may be that receptive areas of association cortex are organized to a considerable extent upon the established significance a particular stimulus has for the animal.

No functional role for the IDR has been described with certainty, but considering that the IDR has characteristics of lability and susceptibility to barbiturates, that it is seen in the unan. esthetized brain but better in the chloralosed brain, etc., and that such characteristics are similar in virtually every respect to those of the long latency responses recorded in association cortex to peripheral stimulation, it is reasonable to assume that such an interhemispheric system can be another means of subjecting this integrative area to widespread influences. $A$ measure of cortical control can also occur via the IDR system at the brainstem. Collateral potentials in the brainstem to peripheral stimulation can either contribute to the occlusion of the IDR relayed discharge or can be completely blocked by a single burst of activity in the interhemispheric system (unpublished). As at the cortex, the important factor is the time between successive stimuli. Defined electrically the functional importance of the IDR system discharging to association cortex appears to be nearly as well established as input from other systems.

The s ole of the MR discharging to association cortex must be evaluated in terms of many factors. This was recently pointed out in great detail by the careful work of Meulders (1962). He emphasized the importance of considering the manner and type of peripheral stimulation, the level of EEGsynchrony or dissynchrony at the moment of MR stimulation and, as we have suggested here, the significance of the stimulation for the animal.

At the present time it is not possible to see more than a glimmer of the possible integrative properties of association cortex. Any comprehensive scheme must certainly take into account areal differences and the apparent foci of electrical discharge to a particular stimulus. Areal differences seem moderately well established. For example, Mickle and Ades (1952) originally described and Berman (1961a and b) explored in detail an auditory-somesthetic association area in the anterior ectosylvian and suprasylvian gyri. This area does not give either the IDR or responses to photic stimulation. Foci for auditory and visual input were described by Buser et al. (1959), for auditory by Thompson and Sindberg (1960), and for somesthetic by Albe-Fessard and Rougeul (1958). However, no cortical foci for responses to somesthetic stimulation were found by Hirsch et al. (1961). Under what conditions the latter authors" "long latency response" may be 
equated with other workers' association cortex responses has not been determined.

To a considerable extent, integrative capacities of association cortex must be based uponacquired associations between natural stimuli and central neuronal activity. For a given population of cortical cells it seems vastly important but hardly sufficient to describe function in terms of such phenomena as converging discharges and synchronized or desynchronized EEG activity. These phenomena are likely to be defined and limited by the anatomical characteristics of a given species. Integration implies plasticity of function. This plasticity must be made possible by changing time relationships between multitudinous stimuli which produce critical moments of occlusion, summation, facilitation, and inhibition.

\section{SIJMMARY}

Cortically recorded evoked potentials to various peripheral and central stimuli were studied in chloralose anesthetized cats. Summation, blocking interaction, and facilitation were investigated by systematic pairing of all possible combinations of two stimuli.

1. From the same locus in association cortex responses were recorded to peripheral, photic, auditory, and somesthetic stimulation and to contralateral cortex and mesencephalic reticular formation (MR) stimulation.

2. Distinct differencesin amount of convergence for the various stimuli was the rule. Photically initiated input was the strongest, followed in or" der of strength by the interhemispheric delayed response (IDR), the response to MR stimulation, and the responses, frequently of equal strength, to auditory and somesthetic stimulation.

3. True facilitation was observed in association cortex by activity originating in the MR.

4. Data support an interpretation of association cortex integrative capacity, based upon plastic, dynamic function accompanying reception of neural discharges from peripheral and central systems.

Preliminary experiments leading to the present report were undertaken in collaboration with Dr. Thelma $T$. Kennedy at the University of Washington. I express my sincere appreciation to Dr. Kennedy for her invaluable help and advice. The competent technical assistance of
Miss Grace Lasterie in all phases of this work is gratefully acknowledged.

\section{REFERENCES}

Albe-Frssard, D. et Rougeul, A. Activités d'ongine somesthésique évoquées sur le cortex non-spécifique du chat anesthésié au chloralose: rầle du centre médien du thalamus. Electroenceph. clin. Neurophysiol., 1958, 10: 131-152.

Amassian, V. E. Studies on organization of a somesthetic -ssociation area, including a single unit analysis. $J$. Neurophysiol., 1954, 17: 39-58.

Berman, A. L. Overlap of somatic and auditory cortical response fields in anterior ectosylvian gyrus of cat. J. Neurophysiol., 1961a, 24: 595-607.

BERMAN, A. L. Interaction of cortical responses to somatic and auditory stimuli in anterior ectosylvian gyrus of cat. J. Neurophysiol., 1961b, 24: 608-620.

BuRNs, B. D. and SMITH, G. K. Transmission of information in the unanesthetized cat's isolated forebrain. $J$. Physiol. (Lond.), 1962, 164: 238-251.

Buser, P. et Borenstein, P. Suppression élective des réponses "associatives" par stimulation réticulaire chez le chat sous anesthésie profonde au chloralose. J. Physiol. (Paris), 1957a, 49: 86-89.

Buser, P. et Borenstein, P. Réponses corticales "secondaires" a la stimulation sensorielle chez le chat curarisé non anesthésié. Electroenceph. clin. Neurophysiol., 1957b, Suppl. 6: 89-108.

Buser, P. et BOREnstein, P. Réponses somesthésiques, visuelles et auditives, recueillies au niveau du cortex "associatif" suprasylvien chez le chat curarise non anesthésié. Electroenceph. clin. Neurophysiol., 1959, II: 285-304.

Buser, P., Borenstein, P. et Bruner, J. Étude des systemes "associatifs" visuels et auditifs chez le chat anesthessit au chloralose. Electroenceph. clin. Neurophysiol., 1959, 11: 305-324.

Buser, P. and ImBert, M. Sensory projections to the motor cortex in cats: a micro-electrodo study. In W.A. Rosenblitith (Editor), Sensory Communication. Wiley, New York, 1961, 607-626.

Dorr, R.W. Potentials evoked in cat cerebral cortex by diffuse and by punctiform photic stimuli. J. Neurophysiol., 1958, 21 : $437-464$.

HirsCh, J. F., ANDERson, R. E., Calvet, J. and Sciterker, $J$. Short and long latency cortical responses to somesthetic stimulation in the cat. Exf. Neurol., 1961, 4: 562-583.

Hotra, T. and TAKENAKA, T. Effect of stimulation of visual cortex on activity of somatosensory corticul neurons. Jap. J. Physiol., 1962, 12: 262-271.

Huares, J. R. Studies on the supracallosal miesial cortex of unanesthetized, conscious mammals. I. Cat. A. Movements elicited by electrical stimulation. Electroenceph. clin. Neurophysiol., 1959, 11: 447-458.

Huohes, J. R. and Mazurowski, J. A. Studies on the supracallosal mesial cortex of unanesthetized, conscious mammals. II. Monkey. A. Movements elicited by electrical stimulation. Electroenceph. clim. Neurophysiol., 1962, 14: 477-485.

Electroenceph. clin. Neurophystol., 1963, 15: 958-968 
IMBert, M. Étude microphysiologiquic des projections sensorielles au niveau du cortex suprasylvien postérieur chez le chat. J. Physiol. (Paris), 1960, 52: 126-127.

JASPER, H. H. and AJMONE MARSAN, C. A stereotaxic atlas of the diencephalon of the cat. Nat. Res. Council of Canada, Ottawa, 1954.

Latimer, C. N. and KenNedy, T. T. Cortical unit activity following transcallosal volleys. J. Neurophysiol., 1961, 24: 66-79.

LI, C.-L. and CHOU, S. N. Cortical intracellular synaptic potentials and direct cortical stimulation. J. cell. comp. Physiol., 1962, 60: 1-16.

LILLY, J. C. Correlations between neurophysiological activity in the cortex and short-term behavior in the monkey. In H. W. Harlow and C. N. WOOLSEY (Editors), Bivlogical and biochemical bases of behavior. University of Wisconsin Press, Madison, 1958, 83-100.

MeuLDERs, M. Etude comparative de la physiologie des voies sensorielle primaires et des voies associatives. These, Université Catholique de Louvain. Arscia, Bruxelles, 1962, 192 p.

MickLE, W. A. and ADEs, H. W. A composite sensory projection area in the cerebral cortex of the cat. Amer. J. Physiol., 1952, 170: 682-689.

MORILLO, A. Micro-electrode analysis of some functional characteristics and inter-relationships of specific association and non-specific thalamo-cortical systems. Eiectroenceph. clin. Neurophysiol., 1961, 13: 9-20.

Rutiedge, L. T. and KenNedy, T. T. Extracallosal delayed responses to cortical stimulation in chloralosed cat. J. Neurophysiol., 1960, 23: 188-196.

RUTLEDGE, L. T. and KENNEDY, T. T. Brainstem and cortical interactions in the interhemispheric delayed response. Exp. Neurol., 1961, 4: 470-483.

Thompson, R. F. and Sindberg, R. M. Auditory response fields in association and motor cortex of cat. J. Neurophysiol., 1960, 23: 87-105.

Reference: RutLEDGE, L. T. Interactions of peripherally and centrally originating input to association cortex, Electroenceph. clin. Neurophysiol., 1963, 15: 958-968. 